\title{
Retrospective Study on Milk Production and Reproductive Performance of Dairy Cattle in a Farm in Selangor, Malaysia
}

\author{
Azhar $\mathrm{H}^{1}$, Zamri-Saad $\mathrm{M}^{1}$, Jesse FFA ${ }^{1}$, Annas $\mathrm{S}^{2}$ \\ ${ }^{1}$ Research Centre for Ruminant Diseases, Faculty of Veterinary Medicine \\ Universiti Putra Malaysia, 43400 Serdang, Selangor, Malaysia \\ ${ }^{2}$ Department of Veterinary Laboratory Diagnosis, Faculty of Veterinary Medicine \\ Universiti Putra Malaysia, 43400 Serdang, Selangor, Malaysia \\ annas@upm.edu.my;mzamri@upm.edu.my
}

\begin{abstract}
Dairy industry is small in Malaysia and unable to fulfill its dairy self-sufficiency. Therefore, Malaysia has to import most of the dairy products to satisfy its domestic demands. This study was performed to evaluate the performance of a selected dairy farm in Malaysia. A dairy farm in Selangor was selected and the farm records between 2011 and 2015 were analysed for the annual milk yield, calving rate and disease occurrence. It was found that the milk yield was low with average annual yield of $44,967 \mathrm{~kg}$ and the average milk production per cow per day was $6.83 \mathrm{~kg}$. Clinical mastitis $(67 \%)$ and traumatic injury $(6.9 \%)$ were the most common disease occurrence. The calving rate of $75 \%$ was within the farm target. Calving percentage and diseases showed significant $(\mathrm{P}<0.05)$ positive and negative influences on milk production, respectively.
\end{abstract}

Key Words: Malaysia, Dairy, Milk, Production, Cattle

\section{INTRODUCTION}

In Malaysia, dairy industry is regarded as small and growing slowly with support from the Department of Veterinary Services (Sim \& Suntharalingam 2015). Therefore, the milk production is still far below the self-sufficiency rate and Malaysia is heavily dependent on imported milk and milk products (Loh 2004). To compensate the demand, there is a need to increase the national milk production through a good farm management for an optimal reproductive performance. Thus, the current performance of dairy farm and its associated risk factors need to be determined and compared with dairy performnace elsewehere before an improved system can be formulated and implemented. The aim of this study is to evaluate a dairy farm's current performance by means of analysing records for milk production, calving rate and disease occurrence.

\section{MATERIAL AND METHODS}

\section{Study background}

A dairy farm located in Selangor, Malaysia was identified and selected for the study. The farm consisted mainly of Friesian cross, Friesian-Jersey and Friesian-Sahiwal breeds, raised in a total area of 16 ha. This area was divided into several paddocks for grazing. The animals were kept extensively within the paddock and were rotated for grazing based on the pasture viability. The main pasture in the grazing area was Brachiaria decumbens but mineral blocks were also provided. During milking, the cattle were provided supplemented feed at the rate of $4 \mathrm{~kg} / \mathrm{animal} /$ day. Milking was done twice daily, at $8.00 \mathrm{am}$ and $4.00 \mathrm{pm}$. The animals were naturally bred at the bull-to-cows ratio of 1:25. 


\section{Data collection}

Farm records between 2011 and 2015 were analysed for milk production, disease occurrence and calving percentage. Field visits were made to gather pre-information data, including the general farm condition, feed, and feeding regime and breeding protocol.

\section{Study parameters}

1. Reproductive parameters

Calving percentage was calculated using the formula below:

$$
\frac{\text { Number of calvings }}{\text { Number of breeder }} \times 100 \%
$$

2. Annual milk production

Annual milk production was calculated by adding the daily milk production in a particular year.

3. Disease incidence

Farm records on diseases and mortality between 2011 and 2014 were analysed for disease and mortality rate.

\section{Data analysis}

The collected data were organised, summarised and analysed using SPSS and presented in tables and graphic forms. Data of the calving percentage and annual milk production, and disease occurrence and annual milk production were analysed for observation of their correlations.

\section{RESULTS AND DISCUSSION}

\section{Results}

\section{Calving rate}

The year 2015 recorded the highest calving percentage at $83.33 \%$ (Table 1). The lowest calving percentage was observed in 2014 with $62.96 \%$. The average annual calving rate for the 5-year study period was $75.6 \%$.

Table 1. Calving rate at the farm between 2011 and 2015

\begin{tabular}{lcccccc}
\hline \hline Year & 2011 & 2012 & 2013 & 2014 & 2015 & Average \\
\hline Total parity & 29 & 22 & 20 & 17 & 20 & 21.6 \\
Average breeding cow & 36 & 27 & 28 & 27 & 24 & 28.4 \\
Calving percentage & 80.56 & 81.48 & 71.43 & 62.96 & 83.33 & 75.6 \\
\hline
\end{tabular}

\section{Milk production}

The year 2012 recorded the highest milk production with $51,143 \mathrm{~kg}$ of milk, while the lowest was in 2014 with 39,256 kg (Figure 1). Nevertheless, the annual milk production between years showed no significant $(\mathrm{P}>0.01)$ difference. Average annual milk production was $44,967 \mathrm{~kg}$, with the average milk production per cow per day at $6.83 \mathrm{~kg}$. 


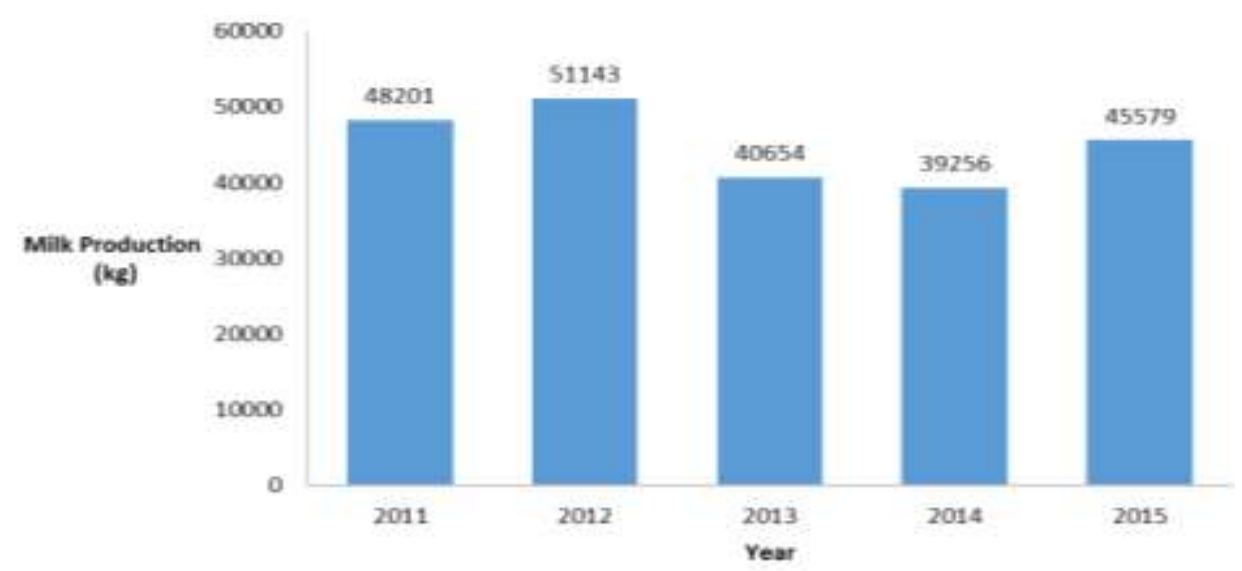

Figure 1. Milk production between 2011 and 2015

\section{Correlation of calving percentage to milk production}

There was a significant $(\mathrm{P}<0.01)$ moderate positive correlation $(\mathrm{r}=0.408)$ between the calving percentage and milk production in 2012 and 2013. In general, in all observed years, positive correlation were observed between the two parameters (Figure 2).

\section{Diseases}

Clinical mastitis and traumatic injury were the two diseases that was observed to be significantly $(\mathrm{P}<0.01)$ high compared to other diseases (Table 2). Other common diseases included lameness, subclinical mastitis, and haemoparasites (Table 2).

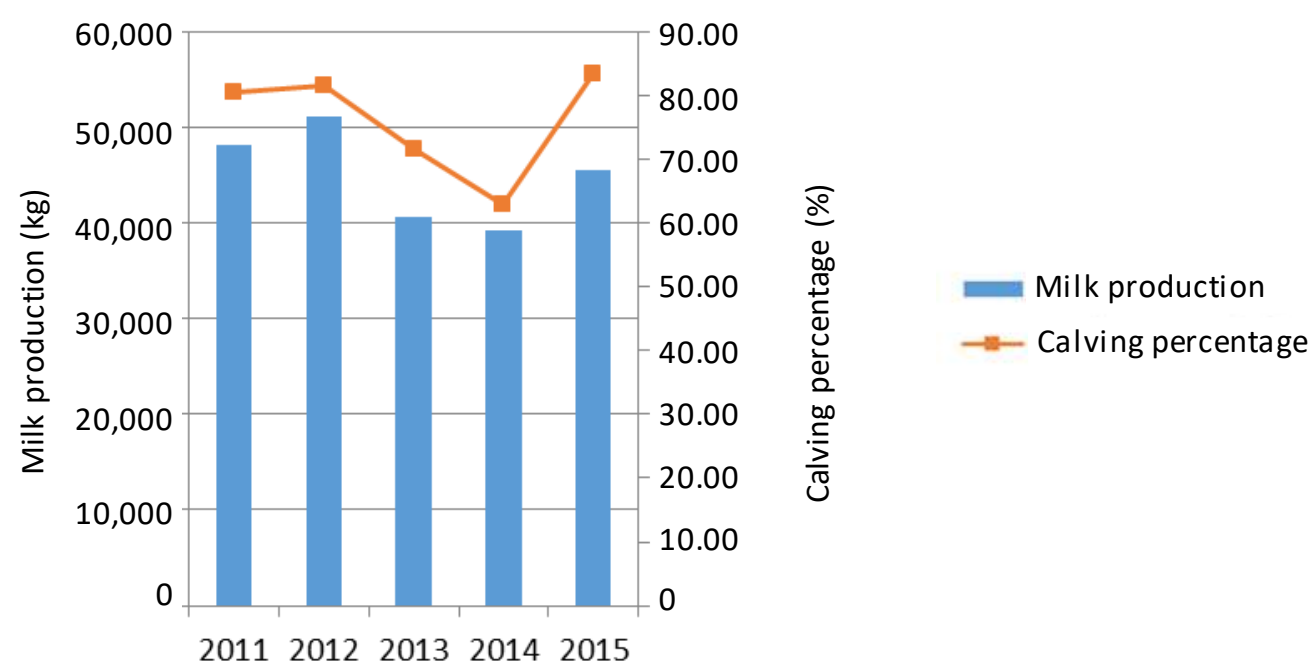

Figure 2. Correlation between annual milk production and calving percentage

\section{Correlation between disease and milk production}

Significantly $(\mathrm{P}<0.01)$ negative correlation between annual milk production and the number of disease cases was observed in years 2012 and 2014 (Figure 3). In general, the negative correlation indicated the higher the occurrence of disease in a year leads to lower milk production in that year and vice versa. 
Table 2. Disease incidence between 2011 and 2015

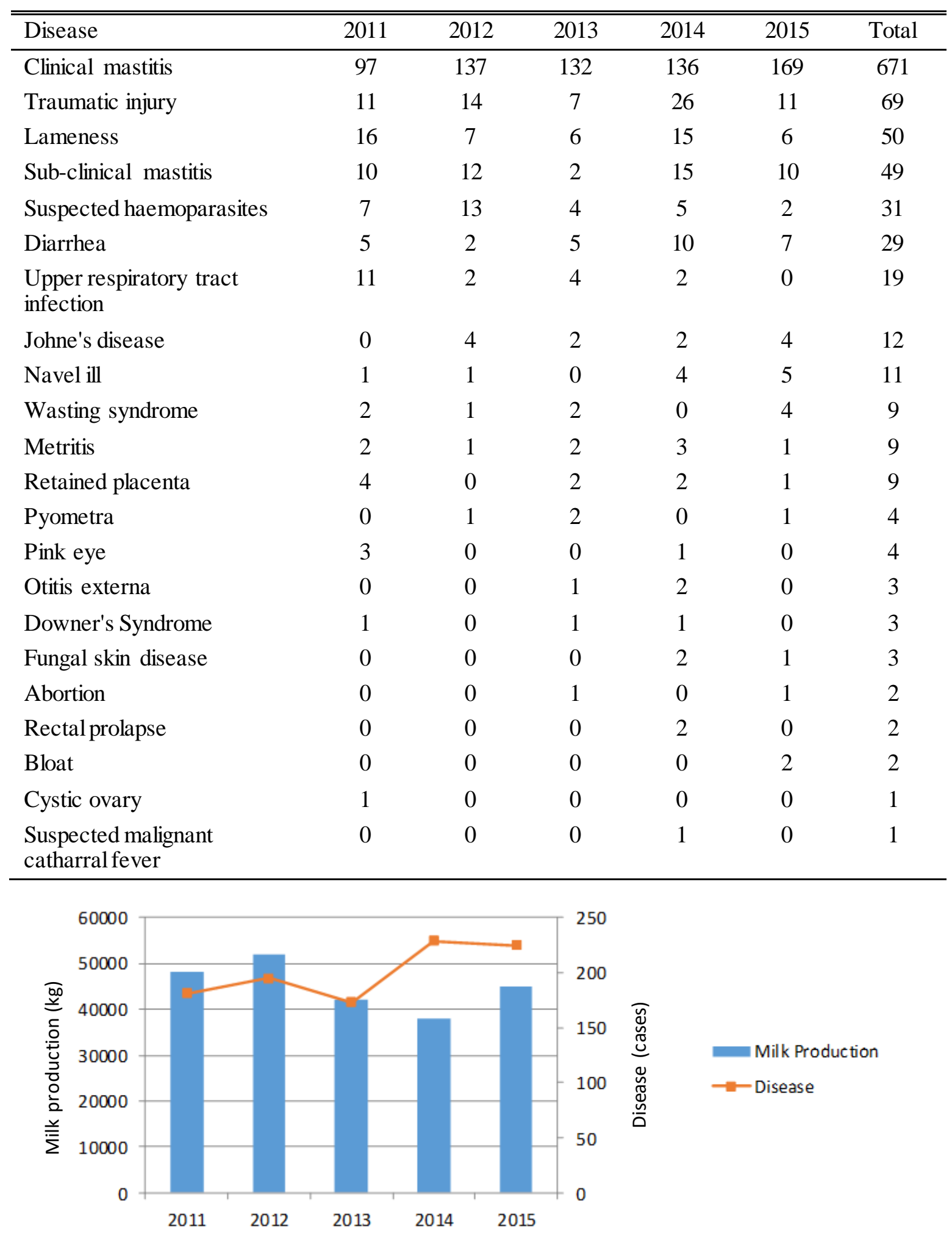

Figure 3. Correlation between annual milk production and annual disease cases

\section{Discussion}

In this study, the selected farm managed to achieve its targeted calving percentage of $60 \%$ although no consistent pattern was observed in the calving percentage during the 5- 
year period. Good calving performances were achieved in 2011, 2012, and 2015. Furthermore, the average annual calving rate of $75.6 \%$ was fairly good (Rasby \& Funston 2016).Using this farm as a model, it is highly suggested that calving rate is one of the most important parameter to evaluate a dairy farm performance. This is in agreement with the findings of Rasby \& Funston (2016). Furthermore, the calving percentage and milk production consistently showed positive correlation, which is interpreted as the higher the number of calf born in a year, the higher the milk yields.

A dairy farm is expected to observed high cases of clinical and subclinical mastitis. As suggested by Biffa et al. (2005), some of the main factors that contribute to high occurrence of mastitis include stage of lactation, age, udder/teat injuries and tick load. In this farm setting, it is postulated that the main cause of traumatic injury and lameness can be associated to the general management of the farm it self. This includes improper facilities, improper maintenance of facilities, improper flooring and perhaps because of bullying. Traumatic injury may in turn injure the teat, leading to mastitis (Qayyum et al. 2016). Other causes of traumatic injury might include fight, sharp objects in the farm and injury during mating. Blood parasites (babesiosis and theileriosis) were quite high in this farms, which was observed earlier among imported purebreds into Malaysia (Sivarajasingam \& Kumar 1989). The Friesian-Jersey and Friesian-Sahiwal breeds in this farm might play significant role in blood parasites infestation. Also, these breeds of imported cattle may also have lower immunity towards tick (Rajput et al. 2005), leading to higher udder tick load leading to mastitis, as well as blood parasite diseases (Biffa et al. 2015). Therefore, proper control of ticks should be formulated for the farm. Meanwhile, lameness was usually secondary to traumatic injury and Downer's syndrome due to hypocalcaemia. It is important to properly handle to reduce the occurrence of diseases.

The average annual milk production was $44,967 \mathrm{~kg}$ with an average milk production per cow per day at 6.831, which were lower than milk production in Indonesia. Morey (2011) revealed that small-scale dairy farmers in Indonesia produce an average of 10 to 12 litres of milk per cow per day. This may be due to several reasons such as the climatic condition in Malaysia where excessive heat and humidity cause heat stress in dairy cows and reduced in milk production (Panandam \& Raymond 2005; Setticari et al. 2007). Actually, $35 \%$ of reduced milk production is due to decreased feed intake while remaining $65 \%$ is attributable to direct effect of heat stress.

\section{CONCLUSION}

In conclusion, the milk yield in this farm was poor compared to other similar farms elsewhere but the calving interval was excellent. Although there was positive correlation between calving rate and milk production, the milk yield was still low probably due to the stronger negative correlation between disease occurrence and milk yield observed in this farm.

\section{REFERENCES}

Biffa D, Debela E, Beyene F. 2005. Prevalence and risk factors of mastitis in lactating dairy cows in Southern Ethiopia. Int J Appl Res Vet Med. 3:189-198.

Loh TC. 2004. Livestock production and the feed industry in Malaysia. In: Protein Sources for the Animal Feed Industry. FAO Expert Consultation and Workshop. Bangkok, $29^{\text {th }}$ April- $3^{\text {rd }}$ May 2002. Rome (Italy): FAO. P. 329-339.

Morey P. 2011. Dairy industry development in Indonesia. Report for International Finance Corporation on Indonesian Industry Development. Morelink Asia Pacific. 
Panandam JM, Raymond AK. 2005. Development of the Mafriwal dairy cattle in Malaysia. AGTR Case Study. Nairobi (Kenya): ILRI.

Qayyum A, Khan JA, Hussain R, Avais M, Ahmed N, Khan A, Kham MS. 2016. Prevalence and association of possible risk factors with subclinical mastitis in Cholistani cattle. Pak J Zool. 48:519-525.

Rajput ZI, Hu SH, Arijo AG, Habib A, Khalid M. 2005. Comparative study of Anaplasma parasites in tick carrying buffaloes and cattle. J Zhejiang Uni Sci. 6:1057.

Rasby R, Funston RN. 2016. Invited review: Nutrition and management of cows: Supplementation and feed additives. Professional Anim Scientist 32:135-144.

Settivari RS, Spain JN, Ellersieck MR, Byatt JC, Collier RJ, Spiers DE. 2007. Relationship of thermal status to productivity in heat-stressed dairy cows given recombinant somatotropin. J Dairy Sci. 90:1265-1280.

Sim RML, Suntharalingam C. 2015. Dairy sector in Malaysia: A review of policies and programs. FFTC Agricultural policy platform [internet]. Available from: http://ap.fftc.agnet.org/ap_db.php?id=501

Sivarajasingam S, Kumar RA. 1989. Distribution and production characteristics of Friesien crossbred cattle in Malaysia. MARDI Res J. 17:91-106. 